\title{
Changes in rainfall regime over Burkina Faso under the climate change conditions simulated by 5 regional climate models
}

\author{
Boubacar Ibrahim • Harouna Karambiri • \\ Jan Polcher • Hamma Yacouba · Pierre Ribstein
}

Received: 29 October 2012/ Accepted: 7 June 2013/Published online: 20 June 2013

(c) The Author(s) 2013. This article is published with open access at Springerlink.com

\begin{abstract}
Sahelian rainfall has recorded a high variability during the last century with a significant decrease (more than $20 \%$ ) in the annual rainfall amount since 1970. Using a linear regression model, the fluctuations of the annual rainfall from the observations over Burkina Faso during 1961-2009 period are described through the changes in the characteristics of the rainy season. The methodology is then applied to simulated rainfall data produced by five regional climate models under A1B scenario over two periods: 1971-2000 as reference period and 2021-2050 as projection period. As found with other climate models, the projected change in annual rainfall for West Africa is very uncertain. However, the present study shows that some features of the impact of climate change on rainfall regime in the region are robust. The number of the low rainfall events $(0.1-5 \mathrm{~mm} / \mathrm{d})$ is projected to decrease by $3 \%$ and
\end{abstract}

B. Ibrahim $(\varangle) \cdot$ H. Karambiri · H. Yacouba Institut International d'Ingénierie de l'Eau et de l'Environnement de Ouagadougou (2iE), BP 594, Ouagadougou 01, Burkina Faso

e-mail: boubacar.ibrahim@1md.jussieu.fr

Present Address:

B. Ibrahim

West African Science Service Center on Climate Change and Adapted Land Use (WASCAL), 06 BP: 9507,

Ouagadougou, Burkina Faso

J. Polcher

Laboratoire de Météorologie Dynamique du CNRS/IPSL,

Université P. \& M. Curie (Paris 6), Tour 45, 3ème étage,

Case 99, 4 pl. Jussieu, 75252 Paris Cedex 05, France

P. Ribstein

UMR 7619 Sisyphe (UPMC-CNRS-EPHE),

Université P. \& M. Curie (Paris 6), Case 123, 4 place Jussieu,

75252 Paris Cedex 05, France the number of strong rainfall events $(>50 \mathrm{~mm} / \mathrm{d})$ is expected to increase by $15 \%$ on average. In addition, the rainy season onset is projected by all models to be delayed by one week on average and a consensus exists on the lengthening of the dry spells at about $20 \%$. Furthermore, the simulated relationship between changed annual rainfall amounts and the number of rain days or their intensity varies strongly from one model to another and some changes do not correspond to what is observed for the rainfall variability over the last 50 years.

Keywords Climate change - Regional climate model . Rainy season - Multiple linear regression - Sahel · Burkina Faso

\section{Introduction}

The first IPCC report on the climate change (Houghton 1990) has triggered a great interest in climate modeling in order to understand climate mechanisms and to evaluate climate evolution at short and long terms under different climate change scenarios (Nakicenovic and Swart 2000; Solomon et al. 2007; Vanvyve et al. 2008). These simulations are implemented at different spatial scales, from the global to the regional, depending on the models and the aims of the studies. However, from regional to global simulations, all climate models project a warmer climate during the 21st century (Prabhakara et al. 2000; Wu et al. 2007; Solomon et al. 2007). Other climate parameters such as rainfall are also projected to change from regional to global scale under a warming condition (Solomon et al. 2009; Wang et al. 2009).

With a focus on West Africa, climate models project different trends for the annual rainfall amount over the $21 \mathrm{st}$ 
century (Hulme et al. 2001; De Wit and Stankiewicz 2006; Paeth et al. 2009). Table 1 summarizes the changes in the annual rainfall amount over the West African Sahel determined from several simulations. These studies show unfortunately a wide range of changes in the annual rainfall amount without any consensus either from the GCMs or from the RCMs.

Altogether, the climate models simulations do not show any consensus in the trends of the annual rainfall amount over West African Sahel during the 21st century even when they are run under the same climate change scenario at a high spatial resolution. With a more detail on the rainy season, a study performed with a regional climate model (REMO) under two scenarios, A1B (intermediate scenario) and B1 (low scenario), Paeth et al. (2009) found a weak change in precipitation over the middle of the current century and a lengthening of dry spells within the seasons. This change of dry spells length within the rainy season despite the unchanged annual rainfall amount shows that an annual analysis of rainfall evolution can hide some changes in the internal of the rainy season that can have significant impacts on water availability and agricultural production. Furthermore, Biasutti and Sobel (2009) found another change in the evolution of the characteristics of the rainy season from the CMIP3 rainfall. They found from an analysis of monthly data, a shortening of the rainy season over Sahel with a delayed season onset of the African monsoon during the 21 st century. Hence, despite these disparities and the uncertainties of the climate models (d'Orgeval et al. 2006; Déqué et al. 2007; Buser et al. 2010) in the evolution of the annual rainfall amount for the future period, a significant insight can be found on the characteristics of the rainy season. Thus, an investigation of the characteristics of the rainy season over the Sahelian region from a fine time step rainfall data is needed for a better understanding of the main changes in the rainy seasons over the future period.
On the other hand, from the observations, an analysis of the variability of rainfall regime over the region made by Le Barbé et al. (2002) and by Laux et al. (2009) showed that changes in two characteristics of the rainy season (number of rainfall events and the mean rainfall amount per event) over 1950-1990 provide an interesting results on this variability. The decrease in annual rainfall amount over the region during the last four decades (Nicholson 2005; Lebel and Ali 2009; Mahé and Paturel 2009) is characterized by a decrease in both rainfall frequency and intensity (Le Barbé et al. 2002; Balme et al. 2005) during the rainy season. However, the rainfall frequency presents the most important contribution to the annual rainfall amount variability over Sahel. The impact of the rainfall frequency (number of rain days) on the annual rainfall amount variability was highlighted by an analysis of daily rainfalls over Niger (Le Barbé and Lebel 1997). Also, crops growth and hydrological cycle depend more on rainy events organization in the rainy season than on the amount of the total rainfalls (Sivakumar 1992; Lebel and Le Barbé 1997; Vischel and Lebel 2007; Modarres 2010). Thus, an analysis of the evolution of rainfall regime over the Sahelian area from the characteristics of the rainy season better highlights the different changes in the rainfall pattern.

In this study, we analyze the evolution of rainfall regime over Burkina Faso, in West African Sahel, with regard to the changes in eight characteristics of the rainy season (date of the season onset, date of the end of season, season duration, number of rain days, mean daily rainfall, maximum daily rainfall, annual rainfall amount, and mean dry spell length). These characteristics are determined throughout a discretization procedure of the rainy season (Ibrahim et al. 2012). Indeed, the eight characteristics relate to the four main components of the rainy season: the rainy season period, the rainfall frequency and intensity and the dry spell lengths. They describe overall the potentialities of the rainy season for crops growth and runoff processes (Barron et al. 2003; Balme et al. 2006), but for this analysis we consider seven

Table 1 Changes in the annual rainfall amount over the 21st century from some studies

\begin{tabular}{|c|c|c|c|c|}
\hline Study & Region & Models & Scenarios & Change \\
\hline Hulme et al. (2001) & Central Sahel & $\begin{array}{l}\text { CCSR-NIES, CGCM1, CSIRO-Mk2, } \\
\text { ECHAM4, GFDL-R15, HadCM2a, NCAR1 }\end{array}$ & $\begin{array}{l}\text { B1-low, B2-mid, } \\
\text { A1-mid and A2-high }\end{array}$ & Significant increase \\
\hline Cook and Vizy (2006) & Sahel & $\begin{array}{l}\text { CM2.1, } \\
\text { MIROC } 3.2, \\
\text { CGCM2.3.2 }\end{array}$ & A2 & $\begin{array}{l}\text { Decrease } \\
\text { Significant increase } \\
\text { Slight decrease }\end{array}$ \\
\hline Paeth and Hense (2004) & Sahel & $\begin{array}{l}\text { ECHAM3 (coupled), ECHAM3/LSG } \\
\text { and HADAM2 }\end{array}$ & $\begin{array}{l}\text { SST scenario and } \\
\text { increase of the GHG }\end{array}$ & Slight decrease \\
\hline Mariotti et al. (2011) & West Sahel & ECHAM5 and RegCM3 & A1B & Decrease \\
\hline \multirow[t]{2}{*}{ Diallo et al. (2012) } & West Sahel & $\begin{array}{l}\text { ICTP-RegCM3, MPI-REMO, METO } \\
\text { HC-HadRM3P }\end{array}$ & A1B & Significant decrease \\
\hline & & SMHI-RCA & & Increase \\
\hline
\end{tabular}

These changes concern periods within 2030-2100 in comparison to 1970-2000 period 
characteristics (the season duration is omitted because it comes from the date of the onset and the date of the end of season). Thus an assessment of the changes in these characteristics under the warmer conditions projected by the climate models will give a detailed insights into the overall impacts of climate changes on the rainy season. The changes in the seven characteristics of the rainy season under the climate change conditions for the IPCC A1B scenario over Burkina Faso are determined from rainfall data produced by five regional climate models (CCLM, HadRM3P, RACMO, RCA, and REMO) run over 1950-2050 period. Meanwhile, the changes in the rainy season are evaluated from a comparison between the characteristics of the rainy season over the reference period of 1971-2000 and those over the projection period of 2021-2050. For each period, a multiple linear regression model (Montgomery et al. 2001; Chen and Martin 2009) is used to describe the relationship between six characteristics of the rainy season and the annual rainfall amount. The assessment of the different relationships would highlight the most important characteristics that significantly determine the evolution of the rainfall regime. So, the regression model method is first implemented on the observed data in order to verify whether the results presented by Le Barbé et al. (2002) for the Sahel are valid for the limited area of Burkina Faso or what has changed since 1990 (last year of Le Barbé et al. (2002) analysis).

\section{Data and methodology}

\subsection{Data and study area}

This study is based on daily rainfall amount recorded and simulated over Burkina Faso. The observed data over
1961-2009 period come from the national network of ten synoptic stations which are well spread over the country (Fig. 1). The advantage of this network is that all the stations present a daily time series of good quality over the considered period (only one year, 1978 is missed at Bogande). The simulated data are produced by five RCMs run under the A1B scenario (Nakicenovic and Swart 2000) for 1950-2050 period, except for RACMO which starts in 1970. Indeed, the five RCMs were chosen from a set of eleven RCMs which have been implemented by ENSEMBLE-Europe (http:// ensemblesrt3.dmi.dk/) for the AMMA program with a condition that the simulations present full daily climate data (rainfall, temperature, humidity, wind speed and radiation) from 1971 to 2050. The list and detail references of the RCMs used are presented in Table 2. The RCMs simulations were performed with a spatial resolution of $50 \mathrm{~km} \times 50 \mathrm{~km}$ and with two boundary conditions (Table 2). For CCLM, RACMO and REMO models, the large scale fields of the ECHAM5-r3 simulation are used as boundary conditions (Kjellström et al. 2011). But, the two other models, HadRM3P and RCA, were run with the HadCM3Q0 outputs as boundary conditions (Kjellström et al. 2011). Furthermore, the five RCMs were implemented over a domain that covers the West African region, longitude: from $35^{\circ} \mathrm{W}$ to $31^{\circ} \mathrm{E}$ and latitude: from $20^{\circ} \mathrm{S}$ to $35^{\circ} \mathrm{N}$.

This analysis is based on the raw data from the five simulations in order to characterize the intrinsic changes that are projected by the RCMs under the A1B scenario over Burkina Faso and other similar climatic zone. Also, the characteristics of the rainy season are determined for each station from observed and simulated daily rainfalls. However, our analyses over the whole country are based on the seasonal average value of the different characteristics over the ten stations.
Fig. 1 Synoptic stations and RCMs grid boxes over Burkina Faso

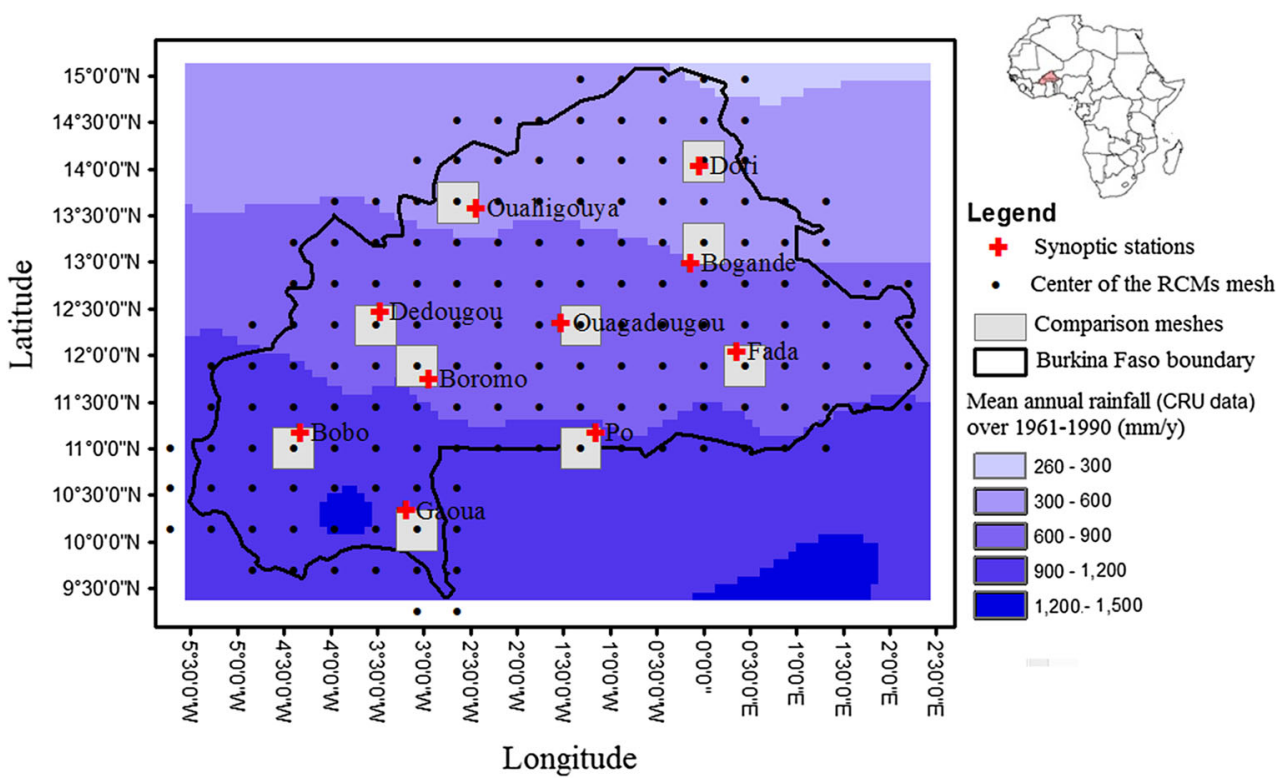


Table 2 References of the five regional climate models

\begin{tabular}{llll}
\hline Institute & Model $(\mathrm{RCM})$ & Driving GCM & Reference \\
\hline HZG & CCLM & ECHAM5-r3 & Rockel et al. (2008) \\
HC & HadRM3P & HadCM3Q0 & Moufouma-Okia and Rowell (2009) \\
KNMI & RACMO & ECHAM5-r3 & Meijgaard et al. (2008) \\
SMHI & RCA & HadCM3Q0 & Samuelsson et al. (2011) \\
MPI & REMO & ECHAM5-r3 & Kotlarski et al. (2010) \\
\hline
\end{tabular}

\subsection{Methodology}

\subsubsection{Definition of the characteristics of the rainy season and their variability}

The rainy season over Burkina Faso is described throughout eight characteristics which highlight the main features and structure of the monsoon over the Sahelian area (Le Barbé and Lebel 1997; Sivakumar 1988, 1992; Barron et al. 2003; Sultan and Janicot 2003; Ibrahim et al. 2012): date of the season onset (Onset), date of the end of season (End), season duration, number of rain days (NbRD), mean daily rainfall (MDR), maximum daily rainfall (MaxR), annual rainfall amount, and mean dry spell length (DryS). For this study, the dry spell is the number of consecutive days with rainfall amount lower than $0.1 \mathrm{~mm}$ (the lowest value recorded in the observations) both for the observations and the simulations. The first two characteristics determined the period of the rainy season from which the other characteristics are derived. However, several methods have been developed for the determination of the date of the season onset and the date of the end of season for the Sahelian area (Sivakumar 1992; Ati et al. 2002; Ibrahim et al. 2012). The statistic method developed by Ibrahim et al. (2012) is used in this study with a daily rainfall threshold of $0.1 \mathrm{~mm} / \mathrm{d}$. The criteria of this method are formulated as follows:

- The season onset is determined after $5 \%$ of the total annual rainfall amount is reached and the end of the season is determined after $95 \%$ of the annual total rainfall amount has fallen;

- The date of the season onset corresponds to the date of the rainfall higher than the average of annual first rainfall events over the entire period. In addition, to be considered, the rainfall event must not be followed by a dry spell longer than the median of the mean dry spell durations at the station or grid point;

- The end of season is marked by a rainfall event occurring after or completing the $95 \%$ of the annual rainfall amount and followed by a dry spell longer than the median dry spell duration at the station or grid point.

Meanwhile, the date of the season onset is a critical characteristic for the sowing period for food production while the second characteristic determines when the crops must reach their stage of maturity (Sivakumar 1992;
Ati et al. 2002). Also, the rainy season period is delimited by the date of the season onset and the date of the end of season (the two characteristics are determined from Ibrahim et al. 2012) from which the season duration is computed. Then, the following four characteristics describe the rainfall frequency and intensity which govern soil moisture and flow intensity along the rivers. Finally, the last characteristic, the mean dry spell length, quantifies the duration of the dry period between consecutive rainfall events. Indeed, long dry spells in a rainy season can lead to crop drying out and poor harvests. Hence, characterizing the changes in these characteristics between two different periods may highlight the changes in the benefits of the rainy seasons in terms of available water resources and agronomic productions. Therefore, the significance of a change in each characteristic between the two periods is assessed with the Wilcoxon test of time series difference assessment (Ansari and Bradley 1960); for a given characteristic, the shift or difference between two periods is significant if the $p$ value is lower than 0.05 .

Furthermore, the comparison periods for the observations are determined through a statistical procedure which splits the full time series into periods of homogeneous data. The procedure is called segmentation (Hubert et al. 1989). The segmentation procedure separates the observed annual rainfall amount time series into wet and dry periods with a significant difference in the magnitude of the annual rainfall amounts for consecutive periods. The procedure is applied for the observed annual rainfall amount time series. But, for the RCMs data, we consider two periods of comparison, the reference period of 1971-2000 and the projection period of 2021-2050. Indeed the projection period is taken with regard to its climate condition which is projected to be warmer than the reference period by the climate models under the climate change condition (Hulme et al. 2001; De Wit and Stankiewicz 2006; Paeth et al. 2011).

\subsubsection{Elaboration of the multiple linear regression of the annual rainfall amount}

The annual rainfall amount is traditionally considered as the main characteristic of the rainy season (Ali and Lebel 2009; Lebel and Ali 2009; Mahé and Paturel 2009) from which the variability of the rainfall regime is usually 
assessed. But, the annual rainfall amount is narrowly linked to the six characteristics of the rainy season (date of the season onset, date of the end of season, number of rain days, mean daily rainfall, maximum daily rainfall, and the mean dry spell length). In this study, the six characteristics are taken as predictors of the annual rainfall amount in order to get a more comprehensive understanding of the rainy season variability that cannot be achieved with the seasonal total rainfalls alone. Thus, a multiple linear regression procedure (Andrews 1974; Brown et al. 1998; Montgomery et al. 2001) is performed in order to reproduce the annual rainfall amount from the six characteristics. This regression modeling aims to present a more complete picture of the rainy seasons over Burkina Faso from the observations during 1961-2009 period and from each of the five simulations. The multiple regression model is built from a sub-set of the six characteristics called the regression model's pertinent variables. These pertinent variables have a none zero coefficients (Eq. 1) determined from two methods over the target period: the deterministic method (Montgomery et al. 2001) and the Bayesian method (Chen and Martin 2009). However, it is presented here the deterministic procedure based on the multiple linear regression model. The linear regression model of the annual rainfall amount is:

$P_{t}=f\left(X_{t}\right)=C+\sum_{j=1}^{6} a_{j} x_{j . t}$

with $P(t)$ the annual rainfall amount for year $t$ ( $t$ the year index), $X_{t}$ vector of the regression model variables at year $t$, $j(1 \leq j \leq 6)$ variable index, $\mathrm{C}$ constant of the regression model, $a_{j}$ the coefficient of variable $j$, and $x_{j . t}$ value of variable $j$ for year $t$.

So, the observed annual rainfall amount regression model is performed over the entire period of the observations (1961-2009) in order to have a large sample, but for the RCMs, a regression model is calibrated over each period from the simulations (reference, $f_{1}, i=1$ with $\mathrm{t} 1=1971-2000$, and projection, $f_{2}, i=2$ with $\mathrm{t} 2=2021-$ 2050) as it is assumed that the factors $a_{j}$ and the coefficient $\mathrm{C}$ can vary between the two periods. The pertinent variables of the regression model are determined through Stepwise procedure (Bendel and Afifi 1977) which eliminates variables that are not statistically significant in the model from the Akaike Information Criterion (this criterion gives the information lost for each candidate model and the pertinent model is the one with low AIC) (Seghouane and Amari 2007). In addition, the significance of the correlation between the selected pertinent variables is assessed with the Pearson test of correlation (Millot 2009). For this test, two variables are significantly correlated when the $p$ value is lower than 0.05 which is reached with a correlation coefficient of about 0.6 . So, the selected pertinent variables must be less correlated and represent the main characteristics of the rainy season that describe the structure of the rainy season over the given period. Also, the representativeness of the regression model over the target period is assessed from its projections with the Wilcoxon test of the difference and the Pearson test for the interannual correlation. The linear regression model is considered valuable over a given period when there is no significant difference between its projections and the annual rainfall amount time series over the period. Then, the returned annual rainfall amount variance from the regression model, R-squared, is computed from the formula of Eq. 2 (Scherrer 1984; Legendre and Legendre 1998). Altogether, the returned variance must be higher than $70 \%$ (significant correlation with Pearson test) for a valuable regression model.

$R^{2}=\sum_{j=1}^{p} \beta_{j} * \rho\left(P, x_{j}\right)$

with $\beta_{j}$ the standardized regression coefficient, $\rho\left(P, x_{j}\right)$ correlation coefficient between $P$ (annual rainfall amount time series over the considered period) and $x_{j}$ (variable $j$ time series over the considered period), the term $\beta_{j} *$ $\rho\left(P, x_{j}\right)$ represents the contribution of variable $j$ to the restituted total variance $\beta_{j} R^{2}$ of the annual rainfall amount from the regression model.

On the other hand, as the regression models $\left(f_{1}\right.$ for the first period and $f_{2}$ for the second period) are built from the time series of the six characteristics over each period and for each RCM, pertinent variables over the reference period and those over the projection period can be different for a given RCM. Thus, the regression model of the reference period can be different with the regression model of the projection period with regard to the pertinent variables and the coefficients. Over all, three cases of pertinent variables sets can be encountered in the two regression models establishment:

- Same subsets of pertinent variables over the two periods, this implies no change in the main characteristics of the rainy season over the two periods (case 1);

- The subset of the pertinent variables of one period is included in the subset of the pertinent variables of the other period; which mean that some changes in the rainy season structure may exist (case 2);

- The two subsets of pertinent variables are different from one period to another, indicating a fundamental change in the structure of the rainy season (case 3 ).

Hence, these differences in the pertinent variables of the two regression models highlight the change in the weight of the relationship between the characteristics of the rainy season and the annual rainfall amount. The significance of the changes in the structure of the rainy season is assessed 
from the performance of each regression model $\left(f_{1}\right.$ and $\left.f_{2}\right)$ over the two periods. This assessment helps also to select the most representative regression model over both reference and projection periods with regard to the change in the annual rainfall amount. But, in case of the two regression models are not representative, a new regression model $(f)$ is calibrated from the merging set of the pertinent variables over the two periods. So, if we call $X_{1}^{*}$ the set of the pertinent variables over the reference period and $X_{2}^{*}$ the set of the pertinent variables over the projection period, the merged pertinent variables over the two periods are $X^{*}=X_{1}^{*} U X_{2}^{*}$. The regression model $f$ is then elaborated from $X^{*}$. Also, the significance of the contribution of the pertinent variables to the change in the mean annual rainfall amount is assessed from a statistical analysis performed through the regression model $f$.

Indeed, for two different periods (significant change in the annual rainfall amount), the regression model $(f)$ is applied from some substitutions of the data over the first period by the data over the second period. For each pertinent variable $\mathrm{j}$, its data over the first period are substituted by its randomly permuted data over the second period. The random permutation of the data is performed in order to break the interannual variability of the given variable over the second period. Thus, for each variable j, 1000 random permutations are performed in order to get a large sample of the data ranking. Then, for each variable $\mathrm{j}$, the fictive projections $\left(P_{1, j}\right)$ from $f$ are generated and compared to $\left(P_{2}\right)$ (main projections over the period 2021-2050 from the regression model $f$ ). Thus, variable $\mathrm{j}$ contributes significantly to the difference in the annual rainfall amount between the two periods if there is no significant difference between the fictive projections $\left(P_{1, j}\right)$ and the main projections $\left(P_{2}\right)$. In addition, an assessment from some simultaneous substitution of two or three variables is also done in case that no single substitution of the variables reproduces the change in the mean annual rainfall between the two periods. The simultaneous substitution of the variables consists in a substitution of the data of the considered variables at the same time with 1,000 random permutations of each variable.

\subsubsection{Assessment of the contribution of the rainy season characteristics to the changes in the annual rainfall amount}

The contribution of each variable to the mean deviation of the annual rainfall amount between the reference and the projection periods is assessed throughout the relative difference of the annual rainfall amount $\alpha=\frac{\left(\overline{P_{t 2}}-\overline{P_{t 1}}\right)}{\overline{P_{t 1}}} \cdot \overline{P_{t 1}}$ mean annual rainfall amount over the first period and $\overline{P_{t 2}}$ mean annual rainfall amount over the second period. Let $\alpha=\sum_{j=1}^{6} \alpha_{j}$ with $\alpha_{j}$ the contribution of variable $j$ to the relative difference of the annual rainfall amount from Eq. 1 .

$$
\begin{aligned}
\alpha=\frac{\left(\overline{P_{t 2}}-\overline{P_{t 1}}\right)}{\overline{P_{t 1}}} & =\sum_{i=1}^{6} \frac{a_{j}\left(\overline{x_{j . t 2}}-\overline{x_{j . t 1}}\right)}{\overline{P_{t 1}}} \\
& \Rightarrow \alpha_{j}=\frac{a_{j}\left(\overline{x_{j . t 2}}-\overline{x_{j . t 1}}\right)}{\overline{P_{t 1}}}
\end{aligned}
$$

$a_{j}$ coefficient of the variable $j$ in the regression model $f, \overline{x_{j . t 1}}$ and $\overline{x_{j . t 2}}$ average values of the variable over the first period and over the second period.

Also, the contributions of five daily rainfall classes to the relative change of the annual rainfall $\delta$ (Eq. 4) are computed from the basic data. The five rainfall classes (Ibrahim et al. 2012) considered in this study are: very low (0.1-5 mm/d), low $(5-10 \mathrm{~mm} / \mathrm{d})$, moderate $(10-20 \mathrm{~mm} / \mathrm{d})$, strong $(20-50 \mathrm{~mm} / \mathrm{d})$ and very strong $(>50 \mathrm{~mm} / \mathrm{d})$. The contribution of each rainfall class to the change in the annual rainfall amount helps to identify which intensities determine the annual rainfall variability over Burkina Faso. Indeed, the annual rainfall amount is computed from the five rainfall classes from $P_{t}=\sum_{k=1}^{5} P C_{k . t}$, with $P C_{k . t}$ the annual rainfall amount for the rainfall class $k$ and $P_{t}$ the annual rainfall amount for year $t$. Let $\overline{P_{t 1}}$ be the average annual rainfall amount from the basic data over the period $i=1,2$ and $\delta c_{k}$ the contribution of the rainfall class $k$ :

$\delta=\frac{\left(\overline{P_{t 2}}-\overline{P_{t 1}}\right)}{\overline{P_{t 1}}}=\sum_{k=1}^{5} \frac{\left(\overline{P c_{k . t 2}}-\overline{P c_{k . t 1}}\right)}{\overline{P_{t 1}}}$

Or

$\delta=\sum_{k=1}^{5} \delta c_{k} \Rightarrow \delta c_{k}=\frac{\left(\overline{P c_{k . t 2}}-\overline{P c_{k . t 1}}\right)}{\overline{P_{t 1}}}$

So, $\frac{\delta c_{k}}{\delta}$ represents the weight of the rainfall class $k$ to the whole variation of the annual rainfall amount between the two periods.

NB: All the analyses done in this study are performed with R software (http://www.r-project.org/).

\section{Historical background of rainfall variability over Burkina Faso}

In this section we focus our analysis on the characteristics of the rainy season interannual variability in Burkina Faso over the 1961-2009 period. The evolution of the rainfall regime is characterized throughout the annual rainfall amount variability in order to identify significant changes that have occurred in the observed records and then their relation with the six characteristics of the rainy season. 
3.1 Annual rainfall variability over the period 1961-2009

An application of the segmentation procedure (Hubert et al. 1989) to the annual rainfall amount time series shows three different homogeneous periods: 1961-1969, 1970-1990 and 1991-2009. The annual rainfall amount presents also different coefficients of variation over the three periods: $8 \%$ for the first period, $10 \%$ for the second period and $11 \%$ for the last period. So, the change in the coefficient of the interannual variability is not significantly different over the three periods. The annual rainfall amount mean decreases are 19 and $9 \%$ respectively over the two last periods in comparison to the first period (Table 3 ). The three homogeneous periods given by the segmentation procedure are in accordance with the results of Ali and Lebel (2009) who showed a rainfall decrease over the Sahelian area from the end of 1960s and the results of Nicholson (2005) and Mahé and Paturel (2009) who found that annual rainfall has increased over the Sahel since the end of 1990s. The three studies highlight that the 1970-1990 period was the driest period over Sahel during the last century. In addition, we compute the normalized index for annual rainfall, number of rain days and mean daily rainfall, with regard to the average over 1961-1969 period, in order to get the annual anomalies.

An analysis of the normalized indexes of three main characteristics of the rainy season (annual rainfall amount, number of rain days and mean daily rainfall) shows two main features for all variables (Fig. 2), a downward trend from 1961 to 1984 and an upward trend from 1985 to 1995 . We notice from Fig. 2, 3 years with an annual rainfall amount deficit of more than $30 \%: 1977,1983$ and 1984. The 1983 is the driest year during the second half of the twentieth century over Burkina Faso with a decrease of $34 \%$ with regard to 1960 s decade. Furthermore, it can be noted on this figure (Fig. 2) that the annual rainfall amount index is much better correlated with the number of rain days index than with the mean daily rainfall index (correlation coefficient of 0.84 for the number of rain days against 0.47 for the mean daily rainfall). The correlation coefficient between the annual rainfall amount and the number of rain days is also higher than that between the annual rainfall amount and the mean daily rainfall over each of the three periods (higher than 0.6 for $\mathrm{NbRD}$ and lower than 0.6 for MDR). Hence, the analysis of the relationship between the annual rainfall amount and the six characteristics of the rainy season should lead for 1961-2009 period to a selection of the number of rain days as the dominant characteristic.

On the other hand, an assessment of the changes in the characteristics between two consecutive periods shows that only the end of season and the mean dry spell length have not significantly changed between the first and the second period (Table 3). But, for the changes between the second and the third period, there is no significant change for four characteristics, the last two characteristics, the season onset and the mean daily rainfall. Altogether, in comparison with the first and the third period, the driest second period is characterized by a delayed season onset (short rainy seasons), a decrease in the number of rain days and in the intensity of the maximum daily rainfall (Table 3).

From the Stepwise procedure of pertinent variables selection for a regression model, the overall six variables were selected to elaborate the regression model (Eq. 1) over the entire observation period (1961-2009). The correlation coefficients between the six variables are lower than 0.6 , which means that the six variables are not closely linked to each other. The regression model reproduces $92 \%$ of the observed annual rainfall variance with a partial contribution of the number of rain days of $56 \%, 16 \%$ for the mean daily rainfall, $11 \%$ for the maximum daily rainfall and the other variables contribute at less than $10 \%$. The multiple regression models' projections present no significant difference with the observed annual rainfall amounts and present a correlation coefficient of about 0.9.

As verification, the Bayesian regression method (Chen and Martin 2009) was also used. It selects three pertinent variables for the regression model: the number of rain days, the mean daily rainfall and the maximum daily rainfall with a likelihood of 0.61 from a set of 10,000 iterations of the Markov Chain Monte Carlo (Gilks 1996). These three variables are also found to be dominant from the deterministic method, thus the Bayesian method confirms the relevance of these variables for the annual rainfall amount regression model. So, the multiple linear regression model built with the deterministic method is more suitable for the regression because of its simplicity and its appropriate description of the different changes in the evolution of the annual rainfall amount.

\subsection{Description of the rainfall regime evolution during the period of 1961-2009}

In order to compare the contribution of the changes in the various characteristics of the rainy season to the annual mean rainfall we will in the following use periods of equal length. First the pre-drought period (1961-1969) will be compared to the driest nine years during the drought (1977-1986). In a second step the recovery of rainfall will be examined with 19 years of the drought period (1972-1990) and the last segment of the time series with equal length (1991-2009).

\subsubsection{Characterization of the annual rainfall amount decrease between 1961-1969 and 1977-1986}

The analyzes of the change from the linear regression model are performed between 1961-1969 period (P1) and 
Table 3 Mean values of eight characteristics of the rainy season from the observations over the three main periods

\begin{tabular}{|c|c|c|c|}
\hline & $1961-1969$ & $1970-1990$ & $1990-2009$ \\
\hline Annual rainfall amount $(\mathrm{mm} / \mathrm{y})$ & 895 & $722(-19 \%)$ & $817(-9 \%)$ \\
\hline Date of the season onset (days) & $12 / 05$ & $21 / 05$ & $16 / 05$ \\
\hline Date of the end of season (days) & $30 / 09$ & $28 / 09$ & $30 / 09$ \\
\hline Season duration (days) & 141 & $130(-8 \%)$ & $137(-3 \%)$ \\
\hline Number of rain days (days) & 53 & $44(-17 \%)$ & $48(-9 \%)$ \\
\hline Mean daily rainfall $(\mathrm{mm} / \mathrm{d})$ & 14 & $13(-7 \%)$ & $13(-7 \%)$ \\
\hline Maximum daily rainfall (mm/d) & 68 & $62(-9 \%)$ & 68 \\
\hline Mean dry spell length (days) & 3 & 3 & 3 \\
\hline
\end{tabular}

The dates of the season onset and the end of season are represented as dates in the format $\mathrm{dd} / \mathrm{mm}$ without year. The bold and italics values: significant change from Wilcoxon test between consecutive periods. The values in bracket represent the relative variation in comparison with 1961-1969 period

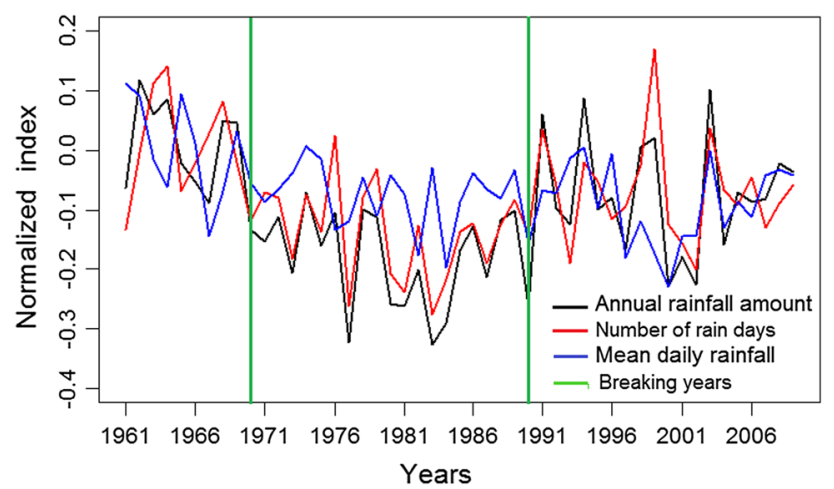

Fig. 2 Evolution of the normalized indexes of three characteristics of the rainy season over Burkina Faso over the 1961-2009 period from the observations. The vertical green lines represent the breaking years produced from the segmentation procedure, 1970 and 1990

1977-1986 period (P2). Figure 3 presents the annual rainfall amount projections from the regression model, the first two boxes (P1 and P2) are the projections from the master data of the two periods. The others boxes represent the projections from the pertinent variables with a substitution of the data (one, two and three variables) for the 1961-1969 period by the randomly permuted values over the 1977-1986 period. The magnitudes of the annual rainfall amount projected with the substituted pertinent variables (from Onset to DryS) are significantly higher than the annual rainfall amount of the dry period (P2). Overall, substituting NbRD produces the highest decrease in the annual rainfall amount, but not enough to reach the magnitude of the period 1977-1986 (Fig. 3). Thus, one variable cannot fully reproduce the decrease in the annual rainfall amount between the two periods. It was found that combining the substitution of NbRD with either MDR (NbMD) or MDR and MaxR (NbMDMa) was needed in order to reproduce the full magnitude of the rainfall reduction over $\mathrm{P} 2$. Even if the decrease in the annual rainfall amount is explained mainly by a decrease in number of rain days, the magnitude of the decrease in the annual rainfall amount is obtained by the simultaneous impact of the decreases in three characteristics: number of rain days, mean daily rainfall and maximum daily rainfall.

The three variables contribute significantly to the annual rainfall amount decrease between the two periods. From Eq. 3, we compute a contribution of $58 \%$ due to the number of rain days, $24 \%$ due to the mean daily rainfall and $8 \%$ due to maximum daily rainfall. So, the three variables reproduce about $90 \%$ of the mean shift of the annual rainfall amount between the two periods. The significant delay of the season onset (Table 3 ) does not contribute significantly to the decrease in the annual rainfall amount because of the low correlation between the two characteristics $(-0.25)$. Overall, from the regression model, the number of rain days represents the main characteristic that lowered the annual rainfall amount over the second period. This characteristic has decreased by about $15 \%$ during the second period compared with the first period. The mean daily rainfall and the maximum daily rainfall have both decreased by 8 and $9 \%$, respectively.

Further to that, the annual rainfall amount decrease concerns all rainfall classes but at different levels. From Eq. 4, the contributions to the decrease in the annual rainfall amount are determined are presented in Table 4. So, the strong rainfall class determines the changes in the annual rainfall amount between the two periods with a contribution at about $57 \%$. However, the pattern is not the same for the decrease in the number of rain days, where the contributions of the four rainfall classes are significant. Thus, the strongest changes in the number of rain days occur in the $10-50 \mathrm{~mm} / \mathrm{d}$ part of the rainfall spectrum. In addition, a monthly analysis (not shown) of the number of rain days shows a significant decrease of rainfall frequencies at the core of the rainy season, June, July and August (decrease of about $15 \%$ over the period 1977-1986 compared with the mean values over 1961-1969 period). 


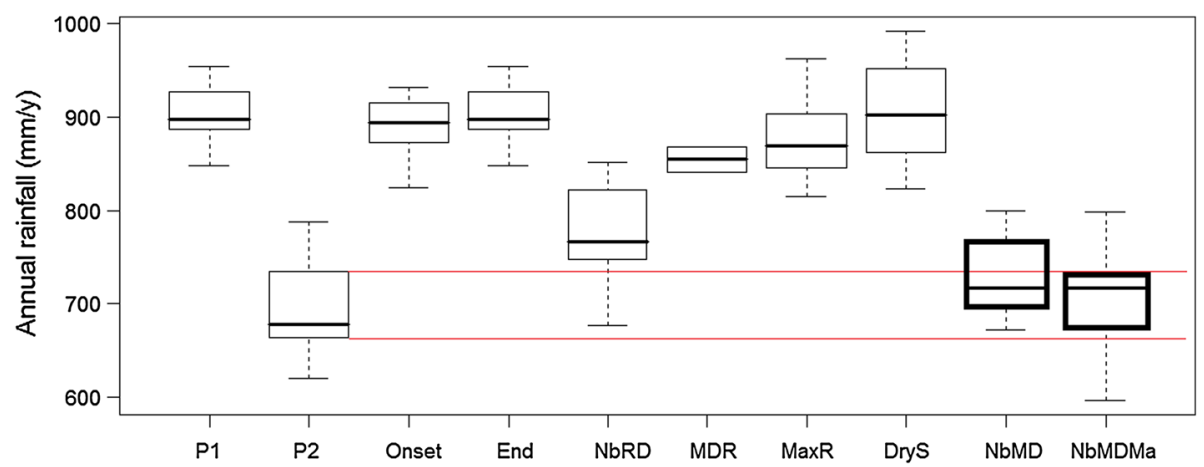

Fig. 3 Impact of the characteristics of the rainy season on the magnitude of the annual rainfall amounts over the period 1977-1986 from the observations. The whisker boxes represent the full time series; the bottom whisker represents the minimum between the minimum of the time series and the median $-1.5 \Delta \mathrm{Q}(\Delta \mathrm{Q}$ represents the interquartile), the first quartile ( $25 \%)$ is the bottom of the box, the median (bold dash), the third quartile ( $75 \%$ ) is the top of the box and the top whisker represents the minimum between the maximum of the time series and the median $+1.5 \Delta \mathrm{Q}$. P1 1961-1969 period, P2 1977-1986 period, Onset substitution of the date of the rainy season onset, End substitution of the date of the end of the rainy season,

\subsubsection{Characterization of the annual rainfall amount increase between 1972-1990 and 1991-2009}

Two periods of nineteen years are considered to analyze with the regression model the increase in rainfall from 1972-1990 (P1) to 1991-2009 (P2). Figure 4 shows the impact of the different variables on the projected annual rainfall amount. In contrary to the previous analysis, here the annual rainfall amount projections with the NbRD reached the level of the median of the second period projections even if their magnitude is not enough to reach the level of the third quartile (Fig. 4). The contributions of the other variables are significantly lower than for the second period annual rainfall (P2). Altogether, only projections from the combination of three variables (NbMDMa) reproduce the magnitude of the projections over the second period at a significant level (Fig. 4). For the changes in these characteristics between the two periods, the number of rain days has increased by $8 \%$ over the period 1991-2009. Also the maximum daily rainfall has increased by $9 \%$ in contrary to the mean daily rainfall which still close to that over the 1972-1990 period. This comes from the discrepancies in the changes over the rainfall class mean intensities with a decrease in the low, the mean and
$N b R D$ projections from the substitution of the number of rain days, $M D R$ projections from the substitution of the mean daily rainfall, $\operatorname{Max} R$ projections from the substitution of the maximum daily rainfall, DryS projections from the substitution of the mean dry spell length, $N b M D$ projections from the simultaneous substitution of the number of rain days and the mean daily rainfall, NbMDMa projections from the simultaneous substitution of the number of rain days, the mean daily rainfall and maximum daily rainfall. The red lines indicate the range of the annual rainfall amount of $\mathrm{P} 2$ to be reproduced by the regression model from the substitution of the pertinent variables. The bold box indicates no significant difference with $\mathrm{P} 2$

the strong rainfalls and an increase for the very strong rainfalls.

However, from the regression model, all the six pertinent variables have contributed (Eq. 3) to the annual rainfall amount increase, with $8 \%$ for the date of season onset, $2 \%$ for the date of the end of the season, $60 \%$ for the number of rain days, $6 \%$ for the mean daily rainfall, $13 \%$ for the maximum daily rainfall and $11 \%$ for the mean dry spell length. So, as for the previous analysis on the description of the rainfall decrease, the number of rain days is the variable that contributes the most to the increase in the annual rainfall amount. Thus, even if the maximum daily rainfall has increased over the last period its impact on the annual rainfall amount remains lower than the impact of the number of rain days. On the other hand, the computation of the contribution of the five rainfall classes to the increase in annual rainfall (Eq. 4) shows that overall the classes between 10 and $100 \mathrm{~mm} / \mathrm{d}$ contributes about $90 \%$ to the change in the annual rainfall amount $(9 \%$ due to the mean rainfall class, $58 \%$ due to the strong rainfall class and $23 \%$ due to the very strong rainfall). But, for the annual number of rain days, only the very low class has significantly increased by about $25 \%$. The other rainfall classes frequencies display small increases in their

Table 4 Contribution of the rainfall classes to the changes in the mean annual amount and the mean number of rain days between 1961-1969 and $1977-1986$

\begin{tabular}{lcclcr}
\hline & Very low $(\%)$ & Low $(\%)$ & Moderate $(\%)$ & Strong $(\%)$ & Very strong $(\%)$ \\
\hline Rainfall amount & 3 & 7 & 18 & 57 & 15 \\
Number of rain days & 16 & 18 & 26 & 35 & 5 \\
\hline
\end{tabular}


frequencies but remain lower than those over 1961-1969 period.

The results found in this analysis of daily rainfall correspond well to those Le Barbé et al. (2002) have obtained with another method (leak distribution model) and over the entire Sahel. This confirms the ability of the multiple linear regression model to describe in more detail the evolution of the mean annual rainfall amount and the different characteristics of the rainy season. This procedure will help us to better describe the different changes in the characteristics of the rainy season projected by the five regional climate models for a warmer climate.

\section{Evolution of the rainfall regime from five RCMs}

The climate evolution over the projection period is characterized from the change in the annual rainfall amount produced by the five RCMs. Figure 5 presents the changes in mean annual rainfall produced by the five RCMs and also provides, as a reference, the observed values for the period 1971-2000. It can be noted that CCLM, HadRM3P, RACMO and REMO show a significant overestimation while RCA shows a significant underestimation of the annual rainfall amount for the reference period. Table 5 summarizes the different deviations of the eight characteristics of the rainy season between the simulations and the observations over the reference period. A detailed analysis of these biases is presented in Ibrahim et al. (2012). Meanwhile, the divergences between the five RCMs to reproduce the observations highlight the uncertainties in the climate models simulations to reproduce the West African Sahel rainfalls (Paeth et al. 2011; Karambiri et al. 2011).

The whisker boxes of the annual rainfall amounts in Fig. 5 show that changes in annual rainfall between the reference and the projection period are RCM dependent. An assessment of the different changes highlights three possible cases: an increase for HadRM3P and RACMO, a decrease for CCLM and RCA, and no significant change for REMO. From this small sample it becomes evident that the influence of the driving GCM (Table 2) on the projected rainfall changes by RCMs is small as for the first two cases different lateral boundary conditions (GCM simulations) have been used (Jones et al. 1995, Mariotti et al. 2011). The increasing change concerns the two models which present the two highest mean annual rainfalls over the reference period and the decrease concerns the models which present the two lowest mean annual rainfalls over the reference period. However, the variance of the annual rainfall amounts is significantly homogeneous over the two periods for each RCM with variance ratios between 0.8 and 1.3, and a $p$ value of Fligner-Killeen test (Fligner and Killeen 1976) higher than $10 \%$. So, despite the significant changes in the magnitude of the annual rainfall amounts, the variance of the annual rainfall amounts has not significantly changed between the two periods. The slight increases in the variances over the projection period for CCLM, HadRM3P and RACMO (Fig. 5) are not significant. These divergences between the RCMs in the evolution of the annual rainfall amount correspond to the results of previous studies for the West African region conducted with GCMs and RCMs (Hoerling et al. 2006; Paeth et al. 2009; Biasutti and Sobel 2009). However, despite the disagreement within the CMIP3 models in the evolution of the summer time total rainfall over the 21st century, Biasutti and Sobel (2009) found a robust delay of the rainy season onset in a warmer climate. An analysis of the evolution of rainfall over Burkina Faso throughout the six main characteristics of the rainy season will better highlight the different changes in the rainfall regime even though the impacts on annual rainfall may be small or contradictory. The changes in the different characteristics of the rainy season will be evaluated with regard to the averages over the reference period presented in Table 5 .

4.1 Description of the evolution of annual rainfall amount predictors

\subsubsection{Rainy season start and end dates}

Changes in the dates of the season onset are model dependent. One model, CCLM shows a significant delay of about one week for the projection period while the other RCMs reveal no significant change (Table 6). HadRM3P, RACMO and REMO show a slight delay of few days (less than 4 days) on average while RCA shows no change in the mean date of
Fig. 4 Impact of the characteristics of the rainy season on the magnitude of the annual rainfall amounts over 1991-2009 period from the observations. P1 1972-1990 period, P2 1991-2009 period. The other indications are the same as in Fig. 3

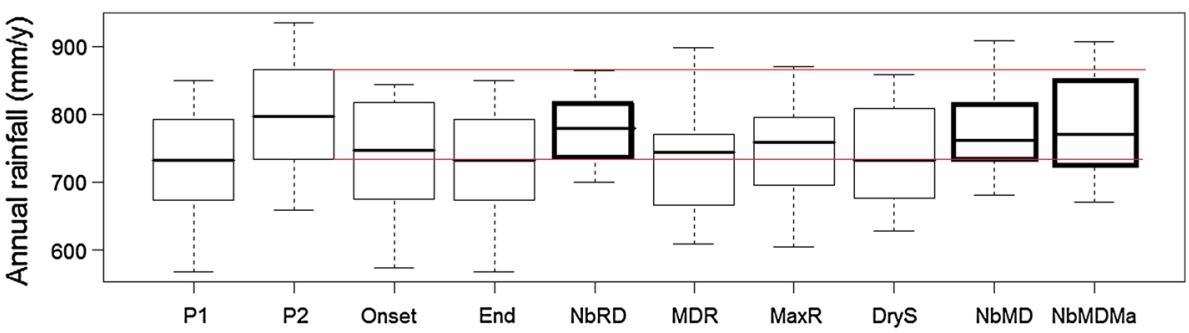


Fig. 5 Magnitudes of the annual rainfall amounts from the five RCMs over the reference and the projection periods. Same as Fig. 3

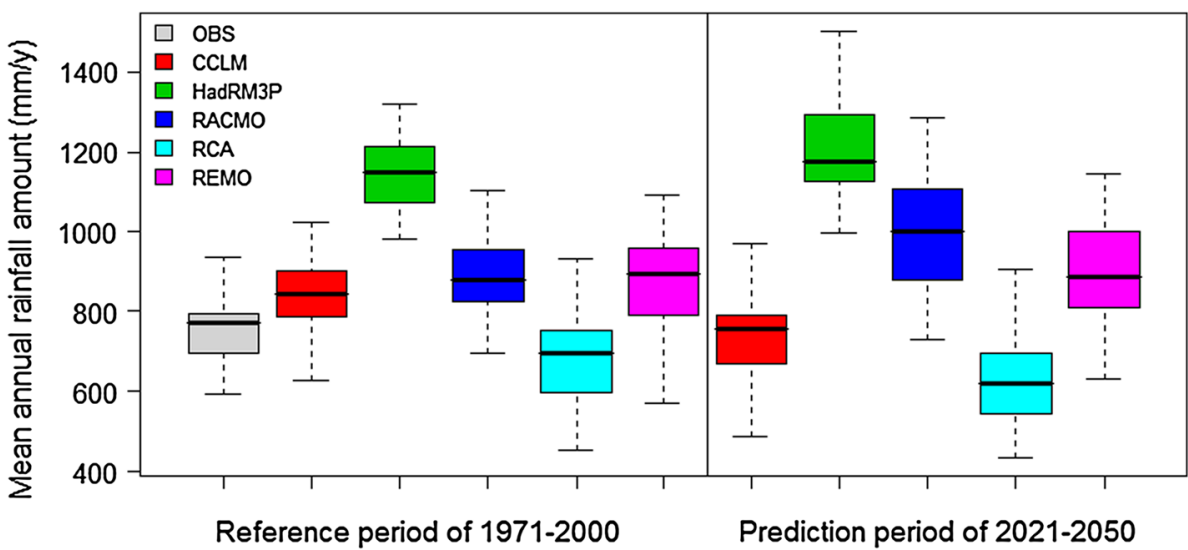

Table 5 Mean values of the rainy season characteristics from the observations and the five RCMs over the reference period 1971-2000

\begin{tabular}{|c|c|c|c|c|c|c|}
\hline & OBS & CCLM & HadRM3P & RACMO & RCA & REMO \\
\hline Annual rainfall amount $(\mathrm{mm} / \mathrm{y})$ & 760 & 840 & 1160 & 900 & 670 & 890 \\
\hline Date of the season onset (days) & 138 & 152 & 105 & 129 & 121 & 143 \\
\hline Date of the end of season (days) & 272 & 279 & 292 & 295 & 271 & 280 \\
\hline Season duration (days) & 134 & 127 & 187 & 166 & 150 & 137 \\
\hline Number of rain days (days) & 46 & 56 & 144 & 116 & 61 & 74 \\
\hline Mean daily rainfall $(\mathrm{mm} / \mathrm{d})$ & 13 & 10.5 & 6.5 & 6 & 7 & 8 \\
\hline Maximum daily rainfall (mm/d) & 64 & 113 & 68 & 92 & 70 & 138 \\
\hline Mean dry spell length (days) & 3 & 2.5 & 2.5 & 2 & 2.5 & 2 \\
\hline
\end{tabular}

the season onset. But for the end of the rainy season, the five RCMs show a general consensus of a delay which is significant for the HadRM3P and RACMO models. The delay of the end of the rainy season in these two models is about one week. Changes in the dates of the end of the rainy season are not significant for CCLM, RCA and REMO; they present a slight delay of a few days on average (Table 6). As a consequence of the impact on the rainy season duration, only CCLM shows a significant shortening of the rainy season by one week, mainly due to the delayed onset. This is in agreement with the change in the observed season duration between the wet period 1961-1969 and the dry period 1970-1990. In contrast, the other RCMs present a slight extension of the rainy season by a few days (less than 4 days) on average. Indeed, from the Fligner-Killeen test, the variances of the rainy season duration haven't significantly changed between the two periods for the five models and the ratios of the variances are between 0.8 and 1.3. The significant delay of the end of the season observed for HadRM3P and RACMO is not enough to produce a significant lengthening of the rainy season because of the noise brought by the onset date. For these models, the rainy season period seems to be delayed without any change in the season duration. Thus the rainy season period is not projected to change significantly in these two models despite their significant increase in the annual rainfall amount.
For the dry spell length evolution, a general consensus comes out of the five RCMs on a lengthening of the dry spells (Table 6). Two models, CCLM and RACMO CCLM and RACMO show a significant increase in the mean dry spell length of more than $5 \%$. The increase in the dry spell length has been found by Karambiri et al. (2011) from a different method of rainy season description. These changes in the mean dry spell length have different origins; decrease in number of rain days for CCLM while for RACMO the lengthening of the season duration is the likely cause. However, the mean dry spell length has remained stable over the observational record despite the significant changes in both rainy season duration and number of rain days.

\subsubsection{Rainfall frequency and intensity}

The number of rain days, the mean daily rainfall and the maximum daily rainfall allow us to better examine how the rain events change with climate. For the changes in the number of rain days (Table 6) only CCLM shows a significant decrease of around $14 \%$ (a decrease of 6.4 days) which is in the range of the observed annual rainfall amount decrease over the two last periods (1970-1990 and 1991-2009) in comparison to the period 1961-1969. The other models only display small changes ranging from an 
Table 6 Changes in the characteristics of the rainy season between 1971-2000 period and 2021-2050 period from the RCMs simulations

\begin{tabular}{|c|c|c|c|c|c|}
\hline & CCLM & HadRM3P & RACMO & $\mathrm{RCA}$ & REMO \\
\hline Date of season onset (days) & +8.6 & +0.5 & +0.5 & -0.3 & +2.4 \\
\hline Date of end of season (days) & +3.5 & +8.4 & +6.1 & +5.9 & +6.8 \\
\hline Season duration (days) & -7.9 & +3.6 & +3.0 & +3.7 & +0.8 \\
\hline Number of rain days (days) & -7 & +0.4 & +1.3 & -3.1 & -2.1 \\
\hline Mean daily rainfall $(\mathrm{mm} / \mathrm{d})$ & +0.1 & +0.6 & +0.7 & -0.1 & +0.3 \\
\hline Maximum daily rainfall $(\mathrm{mm} / \mathrm{d})$ & -0.6 & +7.8 & +19.0 & -1.8 & +2.1 \\
\hline Average length of dry spell (days) & +0.2 & +0.1 & +0.2 & +0.1 & +0.1 \\
\hline
\end{tabular}

The values represent the difference between the averages over the two periods. Bold and italics: significant change from Wilcoxon test

increase of less than $1 \%$ in HadRM3P and RACMO, and a decrease of about $3 \%$ for RCA and REMO. In addition, we analyze the changes in the ratio of the number of rain days over rainy season length to describe how changes in the season duration impacts rainfall frequency. Altogether, there is no change in this ratio for HadRM3P and RACMO in contrast to a decrease in the ratio by $2 \%$ for RCA and REMO and by $4 \%$ for CCLM. Indeed, CCLM, the only model which has a significant shortening of the rainy season presents also the most important decrease in the proportion of rain days. For the mean daily rainfall (Table 6), only RACMO presents a significant change with an increase of $11 \%$. HadRM3P, CCLM and REMO present a slight increase of less than $6 \%$ in contrast to RCA with a slight decrease of about $1 \%$. HadRM3P and RACMO display the same response with an increase in both number of rain days and mean daily rainfall while RCA shows a slight decrease in these two characteristics (Table 6). However, for CCLM and REMO a decrease in the number of rain days can be observed while the mean daily rainfall increases leading to some compensation for the annual mean rainfall (Table 6). The five RCMs present also different changes in the evolution of the maximum daily rainfall. Only RACMO present a significant increase of about $30 \%$. Two models, HadRM3P and REMO present a slight increase (7 and $3 \%$ respectively) while CCLM and RCA present a slight decrease by about $2 \%$. Thus, the changes in the three characteristics (number of rain days, mean daily rainfall and maximum daily rainfall) taken together are different from those observed because four models show an increase in the mean daily rainfall. Only CCLM presents a decrease in both number of rain days and maximum daily rain, consistent with the change found between 1961-1969 and 1970-1990 in the observational record (Table 5).

On the other hand, the two models, CCLM and RCA, which present a decrease in the annual rainfall amount, present opposite signs in the evolution of the mean daily rainfall. In contrast, HadRM3P and RACMO with an increase in the annual rainfall amount present the same type of change over all the seven characteristics (Table 6). Altogether, some consensuses are found on a delayed end of the seasons and a lengthening of the mean dry spells. The first aspect has already been identified in GCMs (d'Orgeval et al. 2006; Biasutti and Sobel 2009).

\subsection{Characterization of rainfall regime evolution from the simulations}

The objective of this section is to estimate the contribution of each of the six characteristics of the rainy season to the change in annual mean rainfall determined in the five RCMs. The pertinent variables for the multiple linear regression model selected by the Stepwise procedure depend on the RCM and the target period (reference or projection). Table 7 presents the contribution of each pertinent variable to the total variance of annual rainfall (Eq. 3). The variances obtained from the regression models $\left(f_{1}\right.$ and $\left.f_{2}\right)$ are overall higher than $90 \%$ which fulfills the requirement set for the methodology. The variance distribution of each regression model (Table 7) shows that the mean daily rainfall is the most important variable for HadRM3P, RACMO, RCA and REMO models and account for more than $70 \%$ of the total variance. But for CCLM, the mean daily rainfall dominates only during the reference period; the number of rain days becomes dominant during the projection period. Thus, the dominant variables in the regression model for annual rainfall of the five RCMs are not the same as for the observations (number of rain days is the dominant variable in that case). Table 7 shows also the modifications of the pertinent variables between the regression models for each RCM over the two periods. Only REMO presents the same pertinent variables over the two periods. Even if there is a modification of the pertinent variables from one period to another for a given RCM, two variables, the number of rain days and the mean daily rainfall are always selected and account for more than $75 \%$ of the total variance (Table 7). Thus, the number of rain days and the mean daily rainfall are the main variables in the projection of the annual 
rainfall amount from the RCMs daily rainfall just as was found for the observations.

Furthermore, the performance of the two regression models $\left(f_{1}\right.$ and $\left.f_{2}\right)$ of each RCM is assessed over the two periods joined together (PP) in order to select the most valuable regression model. The selection criterion is based on the $p$ values of the test for the difference significance and the test for the correlation significance. So, the most valuable model is the one with a $p$ value close to 1 for the Wilcoxon test and a $p$ value close to 0 for the Pearson test. But, in case none of the two regression models is valuable (significant difference and no significant correlation), a new regression model $f$ is generated from the union of the two periods (PP). Table 6 presents the $p$ values of the two tests for the three regression models $\left(f_{1}, f_{2}\right.$ and $f$ ). For four RCMs: CCLM, HadRM3P, RACMO, and RCA, the regressions models $f_{1}$ and $f_{2}$ present significant differences with the regression model for the merged period (PP). Hence, for these RCMs, the regression models are not valuable for the period they have not been calibrated on. Thus, the modification of the pertinent variables in the regression models of these RCMs found in Table 8 reveals a change in the structure of the rainy season.

In the same way as the analysis of the contribution of each variable to the overall variance done before (Table 9), here also the new regression models $(f)$ reproduce over $94 \%$ of the variance of the annual rainfall of the RCMs.
Table 9 presents the contribution of each of the six characteristics (Eq. 3) to the relative difference of annual rainfall. This shows that the decrease in annual rainfall simulated by CCLM comes mainly from a decrease in the number of rain days and the delay of the season onset (Table 9). But, the decrease in the annual rainfall for RCA is explained by the decrease in both number of rain days and the mean daily rainfall amounts. In contrast, the increase of seasonal rainfall in HadRM3P and RACMO originate mainly in an increase of mean daily rainfall. The REMO model, which has no significant change in annual rainfall, is characterized by a positive contribution from the mean daily rainfall and a negative contribution from the number of rain days.

In the following analysis, performed with the regression model $f$, the contribution of each of the six characteristics to the change in annual mean rainfall is quantified through a random permutation of each characteristic for the projection period. Figure 6 presents the annual rainfall amount projected with different combinations of variables. For CCLM, the annual rainfall decrease is mostly explained by the impact of the change in the number of rain days which is the only variable that lowers significantly the annual rainfall from the level of P1 to the one of P2. For HadRM3P and RACMO, the increase in the annual rainfall amount over the second period can be attributed to changes in the mean daily rainfall. For RCA, the amplitude of the decrease in the annual

Table 7 Pertinent variables of the regression models and their contribution (in percentage) to the total variance of the annual rainfall amount

\begin{tabular}{|c|c|c|c|c|c|c|c|c|c|c|}
\hline & \multicolumn{2}{|c|}{ CCLM } & \multicolumn{2}{|c|}{ HadRM3P } & \multicolumn{2}{|c|}{ RACMO } & \multicolumn{2}{|c|}{ RCA } & \multicolumn{2}{|c|}{ REMO } \\
\hline & $\mathrm{P} 1$ & $\mathrm{P} 2$ & $\mathrm{P} 1$ & $\mathrm{P} 2$ & $\mathrm{P} 1$ & $\mathrm{P} 2$ & $\mathrm{P} 1$ & $\mathrm{P} 2$ & $\mathrm{P} 1$ & $\mathrm{P} 2$ \\
\hline Date of the season onset & 18 & $\mathrm{x}$ & -0.2 & -0.8 & -7 & 8 & $\mathrm{x}$ & -1 & -4 & -9 \\
\hline Date of the end of season & -0.8 & $\mathrm{x}$ & -0.2 & -1.2 & -0.1 & 1 & $\mathrm{x}$ & $\mathrm{x}$ & 3 & 5 \\
\hline Number of rain days & 35 & 52 & 21 & 10 & 4 & 8 & 9 & 8 & 18 & 7 \\
\hline Mean daily rainfall & 42 & 35 & 76 & 89 & 93 & 75 & 89 & 86 & 73 & 75 \\
\hline Maximum daily rainfall & $\mathrm{x}$ & 5 & $\mathrm{x}$ & $\mathrm{x}$ & 8 & 7 & $\mathrm{x}$ & 5 & 5 & 17 \\
\hline Mean dry spell length & $\mathrm{x}$ & $\mathrm{x}$ & $\mathrm{x}$ & 0.8 & $\mathrm{x}$ & -1 & $\mathrm{x}$ & $\mathrm{x}$ & $\mathrm{x}$ & $\mathrm{x}$ \\
\hline Explained variance $(\%)$ & 94 & 92 & 97 & 98 & 98 & 98 & 98 & 98 & 95 & 95 \\
\hline
\end{tabular}

P1 = Reference period 1971-2000, P2 = Projection period 2021-2050, $\mathrm{x}=$ variable not selected for the regression model

The bold values indicate the dominant variable in the regression model of the given period

Table 8 Performance of the regression models from the $p$ values of Wilcoxon test and Pearson test

\begin{tabular}{|c|c|c|c|c|c|c|c|c|c|c|c|c|c|c|c|}
\hline & \multicolumn{3}{|c|}{ CCLM } & \multicolumn{3}{|c|}{ HadRM3P } & \multicolumn{3}{|c|}{ RACMO } & \multicolumn{3}{|c|}{$\mathrm{RCA}$} & \multicolumn{3}{|c|}{ REMO } \\
\hline & $f_{1}$ & $f_{2}$ & $f$ & $f_{1}$ & $f_{2}$ & $f$ & $f_{1}$ & $f_{2}$ & $f$ & $f_{1}$ & $f_{2}$ & $f$ & $f_{1}$ & $f_{2}$ & $f$ \\
\hline Wp value & $\mathrm{Lv}$ & Lv & 0.92 & $\mathrm{Lv}$ & Lv & 0.74 & $\mathrm{Lv}$ & $\mathrm{Lv}$ & 0.95 & $\mathrm{Lv}$ & $\mathrm{Lv}$ & 0.73 & 0.3 & 0.3 & 0.94 \\
\hline Pp value & $\mathrm{Lv}$ & $\mathrm{Lv}$ & $<0.01$ & $\mathrm{Lv}$ & $\mathrm{Lv}$ & $\mathrm{Lv}$ & $\mathrm{Lv}$ & $\mathrm{Lv}$ & $\mathrm{Lv}$ & $\mathrm{Lv}$ & $\mathrm{Lv}$ & $\mathrm{Lv}$ & $\mathrm{Lv}$ & $\mathrm{Lv}$ & $\mathrm{Lv}$ \\
\hline
\end{tabular}

$\mathrm{Wp}$ value $=p$ value of Wilcoxon test, Pp value $=p$ value of Pearson test, $f_{1}=$ regression model over the reference period, $f_{2}=$ regression model over the projection period, $f=$ regression model over the two periods, $\mathrm{Lv}=<10^{-3}$

The bold values indicate the high returned variance over the three regression models 
Table 9 Distribution of the changes in the annual rainfall amount within six characteristics of the rainy season for the five RCMs

\begin{tabular}{|c|c|c|c|c|c|}
\hline & CCLM & HadRM3P & RACMO & RCA & $\overline{\text { REMO }}$ \\
\hline Date of season onset (\%) & -2 & -0.1 & -0.3 & +0.04 & -0.9 \\
\hline Date of the end of season $(\%)$ & +0.2 & +0.9 & +1.1 & 0 & +0.6 \\
\hline Number of rain days $(\%)$ & -14 & +0.8 & +0.4 & -3.6 & -2.3 \\
\hline Mean daily rainfall $(\%)$ & +0.3 & +5.2 & +8.8 & -2.3 & +3 \\
\hline Maximum daily rainfall (\%) & 0 & 0 & +1.3 & 0 & +0.3 \\
\hline Mean dry spell length (\%) & 0 & -0.1 & -0.3 & 0 & -0.2 \\
\hline
\end{tabular}

The bold values represent the highest contribution for each RCM

rainfall can only be reproduced by combining the number of the rain days and mean daily rainfall. Indeed, each of these variables has lowered the annual rainfall projected for the second period (Fig. 6). However, for REMO, the two variables (the number of the rain days and the mean daily rainfall) act on the annual rainfall amounts in opposite directions: while the number of rain days lowers the mean annual rainfall, the mean daily rainfall increases it. Only the combination of the two variables produces the near zero change of total rainfall produced by this model. For all RCMs, the variance of the annual rainfall amount does not change significantly between the two periods as demonstrated by the Fligner-Killeen test.

Altogether, significant changes in annual rainfall amount produced by the five RCMs are dominated by changes in the number of rain days and/or the mean daily rainfall intensity. This corresponds to what has been found for the observation records as well and demonstrates that the models are able to pick-up this sensitivity of the rainy season of the Sahel.

\subsection{Changes in daily rainfall for different intensities}

The changes in the total number of rain days and in the mean daily rainfall intensity are not homogeneously distributed over the spectrum of the rainfall intensities. These changes may concern only part of the five rainfall classes defined in the methodology. Thus, for each RCM, the variation for each rainfall class is computed relative to the average over the five rainfall classes for the reference period. The relative variation for the rainfall class $k$ is: $\lambda_{k}=\frac{\Delta N c_{k}}{\overline{N_{1}}} * 100$ with $\Delta N c_{k}$ difference of the numbers of rain days between the two periods for rainfall class $k$ and $N_{1}$ average number of rain days over the reference period and a given RCM (Table 3). The same formula is used for the mean daily rainfall, with $\Delta P c_{k}$ the difference of the mean daily rainfall and $P_{1}$ the average of the mean daily for the reference period (Table 5).

Table 10 presents the relative variations in each rainfall class and RCM. CCLM presents the most important decrease in the number of rain days and this decrease concerns all rainfall classes even if the very low rainfalls record the highest variation. But for the mean daily rainfall of this RCM, only the very strong rainfall class displays an increase. Thus, the slight increase in the mean daily rainfall presented by CCLM in Table 6 is due to an increase in the intensity of rainfalls higher than $50 \mathrm{~mm} / \mathrm{d}$. The significant increase in the mean daily rainfall for HadRM3P and RACMO (Table 6) is mainly attributed to an increase in the very strong rainfall intensity (Table 10). On the other hand, Table 10 shows that HadRM3P and RACMO, two models without any significant changes in the total number of rain days (Table 6), present two rainfall classes with significant change in the partial number of rain days. Finally, for REMO, despite the decrease in the total number of rain days, the very strong rainfall class has slightly increased in number in contrast to the other rainfall classes.

Altogether, two cases of one type of change are found with a decrease in the number of rain days over all rainfall classes for CCLM and RCA (Table 10). Thus, change in the mean values of the number of rain days and in the mean daily rainfall does not mean a single type of change over all rainfall thresholds. Also, from Tables 5 and 10 two RCMs with the same type of change in the annual rainfall amount can present different combinations of type of change over the rainfall classes. However, the only consensus that comes out from the change in the five RCMs rainfall classes is a decrease in the number of the low rainfalls $(0.1-5 \mathrm{~mm} / \mathrm{d})$. The second largest change concerns four RCMs (CCLM, HadRM3P, RACMO, REMO) with an increase in the very strong rainfalls $(>50 \mathrm{~mm} / \mathrm{d})$.

\section{Summary}

The structure of the rainy seasons is described in this study through a set of eight characteristics: date of the season onset (Onset), date of the end of season (End), season duration (SDR), number of rain days (NbRD), mean daily rainfall (MDR), maximum daily rainfall (MaxR), annual rainfall amount, and mean dry spell length (DryS). The seven characteristics address the main components of the rainy season 
Fig. 6 Impact of each variable on the change in the annual rainfall amount of each $\mathrm{RCM}$ between the reference and the projection periods. The point represents the average of the time series, the red line represents the level of the average of the projections of P2 from basic data and the whiskers represent the standard deviation of the time series. $P 1$ Reference period 1971-2000, $P 2$

Projection period 2021-2050
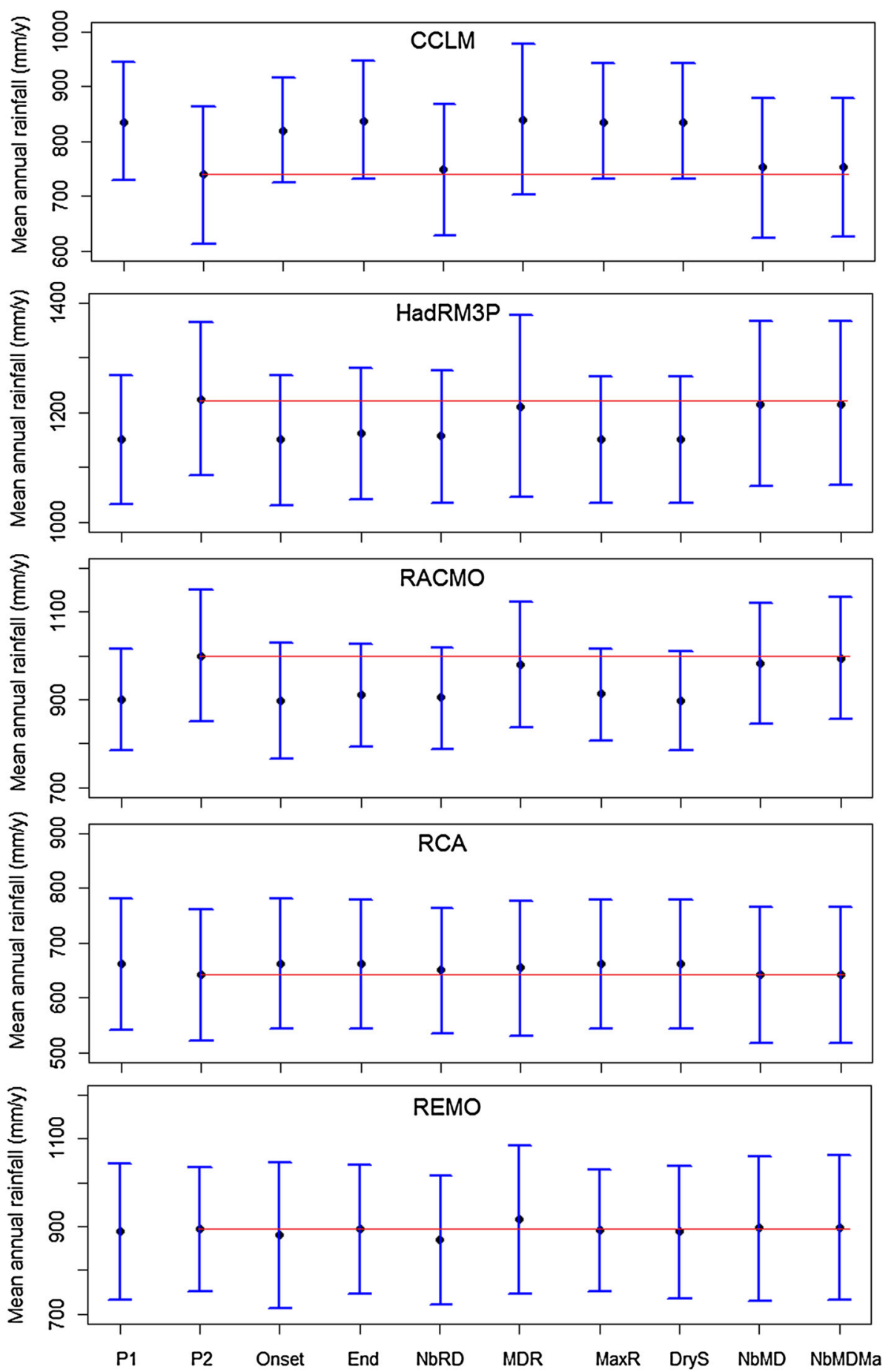

over Sahel and allow to address properties of the rainy season more relevant for application as agricultural yields and water resources in the region. The characterization of the interannual variability of the observed and simulated rainfall over Burkina Faso is done with the multiple linear regression based on six characteristics of the rainy season (Onset, End, NbRD, MDR, MaxR, and DryS).

The linear multiple regression revealed that NbRD is the main characteristics of the rainy season that highlights the different changes in annual rainfall amount over Burkina Faso during 1961-2009 period as was found in previous studies for the Sahelian area (Le Barbé et al. 2002). However, even if MDR has decreased during the drought period, it contributes less than NbRD to the variability of the annual rainfall amounts. Also, despite the significant increase in MaxR from the period 1970-1990 to the period 1991-2009 its contribution to the increase in the annual rainfall amount over the last two decades is less important than that from 
Table 10 Distribution (in percentage) of the changes in the number of rain days and in the mean daily rainfall among the different rainfall classes for each RCM

\begin{tabular}{|c|c|c|c|c|c|c|c|c|c|c|}
\hline & \multicolumn{5}{|c|}{ Number of rain days } & \multicolumn{5}{|c|}{ Mean daily rainfall } \\
\hline & CCLM & HadRM3P & RACMO & RCA & REMO & CCLM & HadRM3P & RACMO & RCA & REMO \\
\hline Very low (\%) & -7.4 & -2.4 & -0.6 & -2.8 & -1.1 & -0.5 & 0 & 0 & 0 & 0 \\
\hline Low $(\%)$ & -2 & +0.1 & +0.6 & -0.7 & -0.9 & -0.8 & 0 & 0 & 0 & 0 \\
\hline Moderate $(\%)$ & -1.4 & +2 & -0.1 & -0.8 & -0.6 & -1 & 0 & +0.1 & 0 & +0.1 \\
\hline Strong $(\%)$ & -1.3 & +0.6 & +0.3 & -0.7 & -0.5 & -0.1 & -0.1 & +0.8 & -0.1 & +0.3 \\
\hline Very strong (\%) & -0.4 & 0 & +1 & -0.1 & 0.2 & +35 & +9.3 & +11 & -1.3 & +3.4 \\
\hline
\end{tabular}

The variations are calculated in regard to the averages from table 5 for each RCM. The values are in percentage (\%) and significant changes are in bold. Very low $(0.1-5 \mathrm{~mm} / \mathrm{d})$, Low $(5-10 \mathrm{~mm} / \mathrm{d})$, Moderate $(10-20 \mathrm{~mm} / \mathrm{d})$, Strong $(20-50 \mathrm{~mm} / \mathrm{d})$, Very strong $(>50 \mathrm{~mm} / \mathrm{d})$

$\mathrm{NbRD}$. So, the increase in the very strong rainfall between the two periods is not enough to dominate the impact of the $\mathrm{NbRD}$ on the change in the annual rainfall amount as suggested by Lebel and Ali (2009) for the Central Sahel $\left(11^{\circ} \mathrm{N}-\right.$ $\left.17^{\circ} \mathrm{N}, 0^{\circ} \mathrm{E}-5^{\circ} \mathrm{E}\right)$. However, in contrary to Diop (1996) who did not detect a significant change in the evolution of SDR over Senegal during 1950-1991, we found that SDR has significantly decreased over Burkina Faso during the dry period 1970-1990 due to a delayed season onset. Indeed, the rainfall frequencies decrease occurs mainly at the core of the rainy season (June, July and August). On the other hand, the multiple linear regression model developed from the observations, produced a reliable representation of the rainy season over Burkina Faso which highlights the dynamics of the characteristics of the rainy season over the period of 1961-2009.

Furthermore, for the variability of the rainfall regime under the climate change condition of the A1B scenario, comparisons performed between the reference period of 1971-2000 and the projection period of 2021-2050, provide a broad range of changes in the characteristics of the rainy season across the five RCMs. The impact of climate change on annual rainfall amount over the ion period is much contrasted as in many previous studies (Dai 2006; Hulme 1994; Johns et al. 2003; Schlosser et al. 2000). Two models, CCLM and RCA project a significant decrease in annual rainfall while HadRM3P and RACMO project a significant increase in annual rainfall for the period 2021-2050. On the other hand, no significant change was found in the evolution of the annual rainfall amount for REMO between the two periods. Thus all the three possible impacts of climate change on the annual rainfall were found over Burkina Faso in these five simulations of regional climate models. This corresponds to the results of Paeth et al. (2011). They found different trends in the evolution of the annual rainfall amount over West Africa for the 21 st century from a set of nine RCMs: an increase in three RCMs, a decrease in three other RCMs, and no significant trend for three other RCMs. Furthermore, in our study, only CCLM presents the same dominant variables in the annual rainfall amount decrease as found from the observations during the last five decades. This model produces also the smallest deviation in the annual rainfall amount when compared to observations. The two models, HadRM3P and RACMO, which present an increase in the annual rainfall amount over the projection period, are characterized by a significant overestimation of the annual rainfall over the reference period. This bias in the simulations of the two models which probably originate in the model's parameterization (Ibrahim et al. 2012) can have significant impact on the models sensitivity to climate change.

However, despite the disparities in the evolution of the annual rainfall amounts for the five RCMs used in this study, a consensus was found on a delay in the end of the rainy season and an increase in the dry spell length. But these characteristics have negligible weights in the determination of the total annual rainfall. The number of rain days (NbRD) and the mean daily rainfall (MDR) are the dominant variables which explain the change in seasonal rainfall as was diagnosed by regression models for the two periods. Indeed, the decrease in annual rainfall amounts is related to a decrease in NbRD for CCLM and to a decrease in both NbRD and MDR for RCA. On the other hand, the increase in the annual rainfall amounts is related to an increase in the MDR for HadRM3P and RACMO. But changes in NbRD and in MDR are not homogeneously distributed over all five rainfall classes for most of the RCMs. Indeed, the increase in MDR for HadRM3P does not concern the strong rainfall $(20-50 \mathrm{~mm} / \mathrm{d})$ and the decrease in NbRD for REMO concerns rainfalls lower than $50 \mathrm{~mm} / \mathrm{d}$. Also, four models: CCLM, HadRM3P, RACMO and REMO show an increase in the strong rainfall intensities.

\section{Conclusion}

The multiple linear regression models developed in this study produced a representative description of the relationships between the annual rainfall amounts and the 
characteristics of the rainy season which matter to applications such as agronomic yields and water resources. The methodology allowed confirming that the continuous drought condition (since 1970) over West African Sahel is characterized by a decrease in rainfall frequencies at the core of the rainy seasons (June to August).

Using climate change projections from 5 regional climate models, the methodology could prove that even though there is no consensus on the evolution of the annual rainfall amount some changes in the characteristics of the rainy season are robust through all projections. The increase in the dry spell length found in all models will be a challenge for agricultural systems (Sivakumar 1992; Laux et al. 2009) and need to be considered by countries as Burkina Faso in the adaptation plans. On the other hand, the delay in the end of the season produced by all models cannot be exploited as it is not significantly related to the total amount of rain brought by the monsoon. The changes in the main characteristics of the rainy season determining annual mean rainfall are very model dependent and thus remain difficult to exploit.

It is well known that the uncertainty in rainfall changes projected over West Africa by regional climate model is just as large as the one of global coupled atmosphere/land/ocean coupled models (Paeth et al. 2011). In our small sample of five RCMs we could not find any dependence of this uncertainty on the driving global climate model. This points towards the atmospheric component or the land surface model, as the main cause of our inability to project with confidence the changes in this monsoonal system. The parameterizations of convection have been highlighted as a source of uncertainty in previous studies (Del Genio et al. 2007; Romps 2011). The results obtained here, in particular the fact that there is little agreement between models on the changes in the characteristics of rainfall events and their synoptic variability, is a further indication that the way convection is represented in our models needs to be examined in more detail. It is thus unlikely that the uncertainty in rainfall changes projected for West Africa will decrease unless the parameterizations of convection are substantially improved (Grandpeix and Lafore 2010) or the resolution of the RCM is sufficiently high to simulate some aspects of convection explicitly.

Acknowledgments The authors would like to thank the "Direction Nationale de la Meteorologie" of Burkina Faso for the rainfall data and the French Ministry of Foreign Affairs for the support to this study through the financial fond of "Fond de Solidarite Prioritaire". We thank also the two anonymous reviewers for their great suggestions and comments that help to improve the quality of the paper.

Open Access This article is distributed under the terms of the Creative Commons Attribution License which permits any use, distribution, and reproduction in any medium, provided the original author(s) and the source are credited.

\section{References}

Ali A, Lebel T (2009) The Sahelian standardized rainfall index revisited. Int J Climatol 29(12):1705-1714. doi:10.1002/joc.1832

Andrews D (1974) A robust method for multiple linear regression. Technometrics 16(4):523-531

Ansari A, Bradley R (1960) Rank-sum tests for dispersions. Ann Math Stat 31(4):1174-1189

Ati O, Stigter C, Oladipo E (2002) A comparison of methods to determine the onset of the growing season in northern Nigeria. Int J Climatol 22(6):731-742. doi:10.1002/joc.712

Balme M, Galle S, Lebel T (2005) Démarrage de la saison des pluies au Sahel: variabilité aux échelles hydrologique et agronomique, analysée à partir des données EPSAT-Niger. Sécheresse 16(1):15-22

Balme M, Vischel T, Lebel T, Peugeot C, Galle S (2006) Assessing the water balance in the Sahel: impact of small scale rainfall variability on runoff: Part 1: rainfall variability analysis. J Hydrol 331(1-2):336-348. doi:10.1016/j.jhydrol.2006.05.020

Barron J, Rockström J, Gichuki F, Hatibu N (2003) Dry spell analysis and maize yields for two semi-arid locations in East Africa. Agric For Meteorol 117(1-2):23-37

Bendel R, Afifi A (1977) Comparison of stopping rules in forward" stepwise" regression. J Am Stat Assoc 72(357):46-53

Biasutti M, Sobel A (2009) Delayed Sahel rainfall and global seasonal cycle in a warmer climate. Geophys Res Lett 36(23):L23707. doi:10.1029/2009GL041303

Brown P, Vannucci M, Fearn T (1998) Multivariate bayesian variable selection and prediction. J R Stat Soc Ser B (Stat Methodol) 60(3):627-641. doi:10.1111/1467-9868.00144

Buser C, Künsch H, Weber A (2010) Biases and uncertainty in climate projections. Scan J Stat 37(2):179-199. doi:10.1111/j. 1467-9469.2009.00686.x

Chen T, Martin E (2009) Bayesian linear regression and variable selection for spectroscopic calibration. Anal Chim Acta 631(1):13-21. doi:10.1016/j.aca.2008.10.014

Cook K, Vizy E (2006) Coupled model simulations of the West African monsoon system: twentieth-and twenty-first-century simulations. J Clim 19(15):3681-3703

d'Orgeval T, Polcher J, Li L (2006) Uncertainties in modelling future hydrological change over West Africa. Clim Dyn 26(1):93-108. doi:10.1007/s00382-005-0079-3

Dai A (2006) Precipitation characteristics in eighteen coupled climate models. J Clim 19(18):4605-4630. doi:10.1175/JCLI3884.1

De Wit M, Stankiewicz J (2006) Changes in surface water supply across Africa with projected climate change. Science 311(5769):1917-1921. doi:10.1126/science.1119929

Del Genio AD, Yao MS, Jonas J (2007) Will moist convection be stronger in a warmer climate? Geophys Res Lett 34(16):L16703. doi:10.1029/2007GL030525

Déqué M, Rowell D, Lüthi D, Giorgi F, Christensen J, Rockel B, Jacob D, Kjellström E, De Castro M, van den Hurk B (2007) An intercomparison of regional climate simulations for Europe: assessing uncertainties in model projections. Clim Chang 81:53-70. doi:10.1007/s10584-006-9228-x

Diallo I, Sylla MB, Giorgi F, Gaye AT, Camara M (2012) Multimodel GCM-RCM ensemble-based projections of temperature and precipitation overWest Africa for the early 21 st century. Int J Geophys ID 972896. doi:10.1155/2012/972896

Diop M (1996) A propos de la durée de la saison des pluies au Sénégal. Sécheresse 7:7-15

Fligner M, Killeen T (1976) Distribution-free two-sample tests for scale. J Am Stat Assoc 71(353):210-213

Gilks W (1996) Markov chain monte carlo. Encyclopedia of Biostatistics 
Grandpeix JY, Lafore JP (2010) A density current parameterization coupled with Emanuel's convection scheme. Part I: the models. J Atmos Sci 67(4):881-897. doi:10.1175/2009JAS3044.1

Hoerling M, Hurrell J, Eischeid J, Phillips A (2006) Detection and attribution of twentieth century northern and southern African rainfall change. J Clim 19:3989-4008. doi:10.1175/JCLI3842.1

Houghton JT, Jenkins GT, Ephraums JJ (1990) Climate change: the IPCC scientific assessment. Cambridge University Press, Cambridge

Hubert P, Carbonnel J, Chaouche A (1989) Segmentation des séries hydrométéorologiques-application ą des séries de précipitations et de débits de l'afrique de l'ouest. J Hydrol 110(3-4):349-367. doi:10.1016/0022-1694(89)90197-2

Hulme M (1994) Regional climate change scenarios based on IPCC emissions projections with some illustrations for Africa. Area 26(1):33-44

Hulme M, Doherty R, Ngara T, New M, Lister D (2001) African climate change: 1900-2100. Clim Res 17(2):145-168

Ibrahim B, Polcher J, Karambiri H, Rockel B (2012) Characterization of the rainy season in Burkina Faso and its representation by regional climate models. Clim Dyn 39(6):1287-1302. doi: 10.1007/s00382-011-1276-x

Johns T, Gregory J, Ingram W, Johnson C, Jones A, Lowe J, Mitchell J, Roberts D, Sexton D, Stevenson D et al (2003) Anthropogenic climate change for 1860 to 2100 simulated with the HadCm3 model under updated emissions scenarios. Clim Dyn 20(6): 583-612

Jones R, Murphy J, Noguer M (1995) Simulation of climate change over Europe using a nested regional-climate model. i: assessment of control climate, including sensitivity to location of lateral boundaries. Q J R Meteorol Soc 121(526):1413-1449

Karambiri H, García Galiano S, Giraldo J, Yacouba H, Ibrahim B, Barbier B, Polcher J (2011) Assessing the impact of climate variability and climate change on runoff in West Africa: the case of Senegal and Nakambe river basins. Atmos. Sci. Lett. 12(1):109-115. doi:10.1002/asl.317

Kjellström E, Nikulin G, Hansson U, Strandberg G, Ullerstig A (2011) 21 st century changes in the European climate: uncertainties derived from an ensemble of regional climate model simulations. Tellus A 63(1):24-40. doi:10.1111/j.1600-0870.2010.00475.x

Kotlarski S, Paul F, Jacob D (2010) Forcing a distributed glacier mass balance model with the regional climate model REMO. Part I: climate model evaluation. J Clim 23(6):1589-1606. doi: 10.1175/2009JCLI2711.1

Laux P, Wagner S, Wagner A, Jacobeit J, Bardossy A, Kunstmann H (2009) Modelling daily precipitation features in the Volta basin of West Africa. Int J Climatol 29(7):937-954. doi:10.1002/joc.1852

Le Barbé L, Lebel T (1997) Rainfall climatology of the HAPEXSahel region during the years 1950-1990. J Hydrol 188:43-73. doi:10.1016/S0022-1694(96)03154-X

Le Barbé L, Lebel T, Tapsoba D (2002) Rainfall variability in West Africa during the years 1950-90. J Clim 15(2):187-202. doi: 10.1175/1520-0442(2002)015

Lebel T, Ali A (2009) Recent trends in the Central and Western Sahel rainfall regime (1990-2007). J Hydrol 375(1-2):52-64. doi: 10.1016/j.jhydrol.2008.11.030

Lebel T, Le Barbé L (1997) Rainfall monitoring during HAPEX-Sahel. 2. Point and areal estimation at the event and seasonal scales. J Hydrol 188:97-122. doi:10.1016/S0022-1694(96)03325-2

Legendre P, Legendre L (1998) Numerical ecology, vol 20. Elsevier, Amsterdam

Mahé G, Paturel J (2009) 1896-2006 Sahelian annual rainfall variability and runoff increase of Sahelian Rivers. Comptes Rendus Geosci 341(7):538-546. doi:10.1016/j.crte.2009.05.002

Mariotti L, Coppola E, Sylla MB, Giorgi F, Piani C (2011) Regional climate model simulation of projected 21 st century climate change over an all Africa domain: comparison analysis of nested and driving model results. J Geophys Res 116:D15111. doi: 10.1029/2010JD015068

Meijgaard E, van Ulft L, van de Berg W, Bosveld FC, van den Hurk B, Lenderink G, Siebesma A (2008) The KNMI regional atmospheric climate model RACMO, version 2.1. Technical report; TR-302, De Bilt, Netherlands

Millot G (2009) Comprendre et réaliser les tests statistiques avec R: Manuel pour les débutants. De Boeck

Modarres R (2010) Regional dry spells frequency analysis by 1-moment and multivariate analysis. Water Resourc Manag 24(10):2365-2380. doi:10.1007/s11269-009-9556-5

Montgomery D, Peck E, Vining G, Vining J (2001) Introduction to linear regression analysis. Wiley, New York

Moufouma-Okia W, Rowell D (2009) Impact of soil moisture initialisation and lateral boundary conditions on regional climate model simulations of the West African Monsoon. Clim Dyn 35(1):213-229. doi:10.1007/s00382-009-0638-0

Nakicenovic N, Swart R (2000) Special report on emissions scenarios. Cambridge University Press, Cambridge, p 598

Nicholson S (2005) On the question of the recovery of the rains in the West African Sahel. J Arid Environ 63(3):615-641. doi: 10.1016/j.jaridenv.2005.03.004

Paeth H, Hense A (2004) Sst versus climate change signals in west african rainfall: 20th-century variations and future projections. Clim Chang 65(1):179-208. doi:10.1023/B:CLIM.0000037508. 88115.8a

Paeth H, Born K, Girmes R, Podzun R, Jacob D (2009) Regional climate change in tropical and northern Africa due to greenhouse forcing and land use changes. J Clim 22(1):114-132. doi: 10.1175/2008JCLI2390.1

Paeth H, Hall N, Gaertner M, Alonso M, Moumouni S, Polcher J, Ruti P, Fink A, Gosset M, Lebel T et al (2011) Progress in regional downscaling of West African precipitation. Atmos Sci Lett 12(1):75-82. doi:10.1002/asl.306

Prabhakara C, Iacovazzi R Jr, Yoo J, Dalu G (2000) Global warming: evidence from satellite observations. Geophys Res Lett 27(21):3517-3520. doi:10.1029/2000GL011719

Rockel B, Will A, Hense A (2008) The regional climate model COSMO-CLM (CCLM). Meteorol Z 17(4):347-348. doi: 10.1127/0941-2948/2008/0309

Romps DM (2011) Response of tropical precipitation to global warming. J Atmos Sci 68(1):123-138. doi:10.1175/2010JAS3 542.1

Samuelsson P, Jones C, Willén U, Ullerstig A, Gollvik S, Hansson U, Jansson C, Kjellström E, Nikulin G, Wyser K (2011) The Rossby centre regional climate model RCA3: model description and performance. Tellus A 63:4-23. doi:10.1111/j.1600-0870. 2010.00478.x

Scherrer B (1984) Biostatistique. Gaëtan Morin, Chicoutimi

Schlosser C, Slater A, Robock A, Pitman A, Vinnikov K, HendersonSellers A, Speranskaya N, Mitchell K (2000) Simulations of a boreal grassland hydrology at Valdai, Russia: PILPS Phase 2 (d). Mon Wea Rev 128(2):301-321. doi:10.1175/1520-0493(2000) 128

Seghouane A, Amari S (2007) The aic criterion and symmetrizing the Kullback-Leibler divergence. IEEE Trans Neural Netw 18(1): 97-106

Sivakumar M (1988) Projecting rainy season potential from the onset of rains in Southern Sahelian and Sudanian climatic zones of West Africa* 1. Agric For Meteorol 42(4):295-305. doi: 10.1016/0168-1923(88)90039-1

Sivakumar M (1992) Empirical analysis of dry spells for agricultural applications in West Africa. J Clim 5(5):532-539

Solomon S, Qin D, Manning M, Chen Z, Marquis M, Averyt K, Tignor M, Miller H (2007) Contribution of working group i to 
the fourth assessment report of the intergovernmental panel on climate change, 2007. IPCC. Cambridge University Press, Cambridge

Solomon S, Plattner G, Knutti R, Friedlingstein P (2009) Irreversible climate change due to carbon dioxide emissions. Proc Natl Acad Sci 106(6): 1704

Sultan B, Janicot S (2003) The West African monsoon dynamics. Part II: the "preonset" and "onset" of the summer monsoon. J Clim 16(21):3407-3427. doi:10.1175/1520-0442(2003)016

Vanvyve E, Hall N, Messager C, Leroux S, Van Ypersele J (2008) Internal variability in a regional climate model over West Africa. Clim Dyn 30(2):191-202. doi:10.1007/s00382-007-0281-6

Vischel T, Lebel T (2007) Assessing the water balance in the sahel: impact of small scale rainfall variability on runoff. Part 2: idealized modeling of runoff sensitivity. J Hydrol 333(2-4):340-355. doi:10.1016/j.jhydrol.2006.09.007

Wang B, Lee J, Kang I, Shukla J, Park C, Kumar A, Schemm J, Cocke S, Kug J, Luo J, Zhou T, Wang B, Fu X, Yun W, Alves O, Jin E, Kinter J, Kirtman B, Krishnamurti T, Lau N, Lau W, Liu P, Pegion P, Rosati T, Schubert S, Stern W, Suarez M, Yamagat T (2009) Advance and prospectus of seasonal prediction: assessment of the apcc/clipas 14-model ensemble retrospective seasonal ion (1980-2004). Clim Dyn 33(1):93-117. doi:10.1007/ s00382-008-0460-0

Wu H, Guiot J, Brewer S, Guo Z (2007) Climatic changes in Eurasia and Africa at the last glacial maximum and mid-Holocene: reconstruction from pollen data using inverse vegetation modelling. Clim Dyn 29(2):211-229. doi:10.1007/s00382-007-0231-3 